ARTÍCULO ORIGINAL

\title{
NEUTRALIZACIÓN DE LA ACTIVIDAD LETAL DEL VENENO DE SERPIENTE Bothrops atrox POR SUERO HIPERINMUNE DE LLAMA (Lama glama)
}

\author{
Henri Bailon Calderon (101,a, Elizabeth Gaby Colque Alave (1),b,

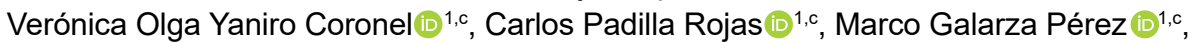 \\ Omar Alberto Cáceres Rey $\mathbb{1}^{1, c}$, César Bonilla Ferreyra®2,a, Benigno Tintaya Felix $\circledast^{2, b}$, \\ David García Neyra (D) 1,d, Rosalina Rosio Inga Arellano (D) 2,a, Silvia Seraylan Ormachea (iD) 2 , \\ Harrison Montejo Arevalo (iD ${ }^{1, \mathrm{e}}$ \\ 1 Laboratorio de Referencia Nacional de Biotecnología y Biología Molecular, Centro Nacional de Salud Pública, Instituto
Nacional de Salud, Lima, Perú.
2 Centro Nacional de Producción de Biológicos, Lima, Perú.
${ }^{a}$ Biólogo, magíster en Bioquímica y Biología Molecular; ${ }^{\text {b }}$ médico veterinario; ' biólogo; d técnico de laboratorio; ${ }^{\text {e }}$
administrador
}

\section{RESUMEN}

Objetivos: Evaluar la capacidad del suero hiperinmune de llama (Lama glama) para neutralizar la letalidad del veneno de la serpiente Bothrops atrox en ratones de laboratorio. Materiales y métodos: Se calculó la dosis letal media $\left(\mathrm{DL}_{50}\right)$ de un pool de venenos de serpientes de Bothrops atrox de Perú, y se midieron los títulos de anticuerpos por ensayo ELISA; así como la potencia de neutralización del suero inmune por el cálculo de la dosis efectiva media $\left(\mathrm{DE}_{50}\right)$ durante el periodo de inmunización. Resultados: $\mathrm{La}_{\mathrm{DL}}$ del veneno fue de 3,96 $\mu \mathrm{g} / \mathrm{g}$, similar a otros trabajos realizados en Bothrops atrox en Perú. Los títulos de anticuerpos contra el veneno se incrementan rápidamente en la llama mostrando una rápida respuesta inmune; sin embargo, la capacidad de neutralización se incrementa más lentamente y requiere de varias dosis y refuerzos de las inmunizaciones alcanzado una $\mathrm{DE}_{50}$ de $3,30 \mu \mathrm{L} / \mathrm{g}$ ratón y una potencia de neutralización $3,6 \mathrm{mg} / \mathrm{mL}$ después de 15 inmunizaciones. Conclusiones: El suero hiperinmune de llama es capaz de neutralizar la letalidad del veneno de la serpiente Bothrops atrox de Perú en ratones de laboratorio.

Palabras clave: Bothrops atrox; Lama glama; Neutralización; Sueros Inmunes; Dosis Letal 50; Letalidad (Fuente: DeCs BIREME).

\section{NEUTRALIZATION OF THE LETHAL ACTIVITY FROM Bothrops atrox VENOM BY HYPERIMUNE LLAMA SERUM (Lama glama)}

Citar como: Bailon Calderon $\mathrm{H}$, Colque Alave EG, Yaniro Coronel VO, Padilla Rojas C, Galarza Pérez M, Cáceres Rey OA, et al. Neutralización de la actividad letal del veneno de serpiente Bothrops atrox por suero hiperinmune de llama (lama glama). Rev Peru Med Exp Salud Publica. 2020;37(3):44653. doi: https://doi.org/10.17843/ rpmesp.2020.373.4597.

Correspondencia: Henri Bailon Calderon; Av. Defensores del Morro 2268, Chorrillos. Lima, Perú; hbailon@ins.gob.pe

Recibido: $15 / 06 / 2019$

Aprobado: 27/05/2020

En línea: 02/09/2020

\section{ABSTRACT}

Objectives: To evaluate the capacity of the hyperimmune llama serum (Lama glama) to neutralize the lethal activity of Bothrops atrox venom in laboratory mice. Materials and methods: Mean lethal dose $\left(\mathrm{LD}_{50}\right)$ was calculated from a Bothrops atrox venom sample pool from Peru. The antibody titers were measured by ELISA assay; and the immune serum neutralization potency was measured by calculating the mean effective dose $\left(\mathrm{ED}_{50}\right)$ during the immunization period. Results: The venom's $\mathrm{LD}_{50}$ was $3.96 \mu \mathrm{g} / \mathrm{g}$; similar to what was found in other studies about Bothrops atrox carried out in Peru. The titers of antibodies against the venom increased rapidly in the llama, demonstrating a fast immune response; however, the neutralization capacity increased slowly and required several doses and immunization reinforcements, obtaining a $\mathrm{ED}_{50}$ of $3.30 \mu \mathrm{L} / \mathrm{g}$ mouse and a neutralization potency of $3.6 \mathrm{mg} / \mathrm{mL}$ after 15 immunizations. Conclusions: The hyperimmune llama serum is able to neutralize the lethality of the Bothrops atrox venom from Peru in laboratory mice.

Keywords: Bothrops atrox; Lama glama; Neutralization; Immune Sera; Lethal Dose 50; Mortality (Source: MeSH NLM).

\section{INTRODUCCIÓN}

El ofidismo es un síndrome resultante del envenenamiento ocasionado por serpientes venenosas, generalmente de especies pertenecientes a las familias Viperidae y Elapidae ${ }^{(1,2)}$. En el 
Perú, se conoce a la serpiente Bothrops atrox como la especie de mayor importancia médica, responsable del $88 \%$ al $92 \%$ de los casos de ofidismo en el país ${ }^{(1,3)}$, causa morbimortalidad y deja secuelas como amputaciones o laceraciones en las partes afectadas. El daño tisular se debe a un conjunto de actividades biológicas producidas por enzimas presentes en el veneno, como el efecto proteolítico -destrucción de proteínas especialmente estructurales- coagulante, vasculotóxico y nefrotóxico ${ }^{(4)}$.

El cuadro clínico se caracteriza por dolor, edema, equimosis, eritema y necrosis. En los casos graves pueden presentarse vesículas o ampollas de contenido seroso y hemorrágico, así como hematemesis y choque hemorrágico. El único tratamiento farmacológicamente válido para los casos de ofidismo es la aplicación de inmunoterapia artificial pasiva, mediante la transferencia de anticuerpos IgG antiveneno, generalmente heterólogos, de origen equino ${ }^{(5)}$.

El suero antibotrópico polivalente líquido es elaborado por el Instituto Nacional de Salud (INS) como una solución purificada de inmunoglobulinas específicas IgG completa, obtenidas a partir del plasma de equinos hiperinmunizados con un pool de venenos de las serpientes del género Bothrops, específicamente Bothrops atrox, Bothrops pictus, Bothrops barnetti, Bothrops braziili y Bothrocophias hyoprora ${ }^{(2,3,6)}$.

Actualmente existen algunos problemas asociados a la producción de antídoto contra el veneno de esta serpiente, como la necesidad del uso de serpientes para obtener el veneno, el riesgo implícito en la obtención del veneno, el uso de equinos para la obtención del suero hiperinmune y la posterior extracción de los anticuerpos totales que contienen los anticuerpos neutralizantes del veneno y demás anticuerpos del animal ${ }^{(1,2)}$. Los equinos utilizados sufren a menudo de hepatomegalia, a causa de la inmunización con los venenos. Algunas investigaciones se dirigen a mejorar los procesos fisiológicos y bioquímicos, entre ellos las pruebas con coadyuvantes alternativos que mejoran la liberación y asimilación del veneno dentro del caballo con miras para reducir los efectos negativos de las inoculaciones ${ }^{(5)}$.

Además, los anticuerpos equinos completos contienen la fracción constante en la cadena pesada, reconocida por los receptores de varios tipos celulares, como linfocitos NK, neutrófilos, macrófagos, células $\mathrm{B}$ y mastocitos, y por los factores del complemento; también pueden causar otras reacciones adversas conocidas como enfermedad asociada al suero, que se caracteriza principalmente por urticaria, tos, náuseas y vómitos, taquicardia y dolores de cabeza. Además, en muchos casos el paciente puede desarrollar anafilaxia sistémica con síntomas como hipotensión, broncoespasmo $\mathrm{y}$ angioedema ${ }^{(7)}$.

El objetivo principal de este estudio es determinar la eficacia del suero hiperinmune de llama (Lama glama) como neutralizante de la actividad letal del veneno de serpiente

\section{MENSAJES CLAVE}

Motivación para realizar el estudio: En el Perú existen pocos estudios sobre el uso de animales diferentes al caballo para la producción de antídotos contra la mordedura de serpientes venenosas. Es necesario diseñar y evaluar nuevas alternativas para enfrentar este problema.

Principales hallazgos: El suero hiperinmune de la llama es capaz de neutralizar el veneno de la serpiente Bothrops atrox de forma similar a los antídotos usados actualmente para este tipo de serpiente.

Implicancias: Si se realizan más estudios y se demuestra la eficacia del suero de llama para la producción de antídotos, podría contarse con una nueva alternativa para la producción de antídotos antibotrópicos.

peruana Bothrops atrox; además aportará conocimiento de nuevas alternativas de producción de biológicos, lo cual contribuirá con la capacidad de producción de antiofídicos por el Instituto Nacional de Salud del Perú.

\section{MATERIALES Y MÉTODOS}

El presente estudio es de tipo experimental analítico.

\section{Animales de experimentación}

Se empleó un ejemplar de llama (Lama glama) macho para obtener el suero preinmune y posinmune. El animal provenía de un centro agropecuario (SAIS Pachacutec), estuvo sano y saludable, pasó un periodo de evaluación veterinaria y cuarentena de 40 días, previo a la experimentación. Se emplearon ratones $\mathrm{BALB} / \mathrm{c}$ (Mus musculus) de $17 \mathrm{~g}$ a $19 \mathrm{~g}$ del bioterio del Centro Nacional de Producción de Biológicos del INS, los cuales fueron mantenidos en un ambiente controlado del laboratorio. El manejo de los ratones se realizó siguiendo lo descrito en la Guía de manejo y cuidado de animales de laboratorio: ratón, del INS ${ }^{(8)}$.

\section{Procedimientos}

\section{Obtención y conservación del veneno}

Las muestras de veneno se obtuvieron por extracción manual, fueron recogidas en un vaso de precipitados y se transportaron al laboratorio en cadena de frío. Se centrifugaron a $5000 \mathrm{rpm}$ por 20 minutos para eliminar los componentes extraños al veneno y se tomaron alícuotas de $2 \mathrm{~mL}$ en viales de vidrio. Los viales se congelaron a $-80^{\circ} \mathrm{C}$ toda la noche, luego fueron colocados en una liofilizadora hasta que se forme una tableta homogénea; se registró el peso neto del veneno liofilizado que se almacenó a $-80{ }^{\circ} \mathrm{C}$ hasta su uso. 


\section{Electroforesis de proteinas por SDS-PAGE}

El veneno se trató con un buffer de proteínas bajo condiciones reductoras durante 5 minutos a $100{ }^{\circ} \mathrm{C}$ para luego ser sometido a electroforesis por el método SDS-PAGE al 12\% durante 1 hora a 100 voltios. Se utilizó un marcador de peso molecular de proteínas (Thermo Scientific \#26623). La tinción del gel se realizó con azul de Coomassie durante 1 hora y luego fue lavado con solución decolorante. En el caso del suero, las condiciones de electroforesis, la tinción y el revelado del gel fueron las mismas que para el veneno.

\section{Determinación del efecto letal medio}

Se preparó la solución madre de veneno a una concentración de $1 \mathrm{mg} / \mathrm{mL}$ empleando como disolvente una solución fisiológica estéril. Se tomaron de referencia los valores de dosis letal media $\left(\mathrm{DL}_{50}\right)$ reportado en estudios previos ${ }^{(12-15)}$ que, para el veneno de Bothrops atrox se reporta en un rango de $3 \mu \mathrm{g} / \mathrm{g}$ a $6 \mu \mathrm{g} / \mathrm{g}$ de ratón. Se prepararon soluciones de mayor y menor cantidad de veneno que el valor de referencia, manteniendo un factor de dilución constante de $1,22 \mu \mathrm{g} / \mathrm{g}$ ratón. Se inoculó por vía intraperitoneal un volumen de $0,5 \mathrm{~mL}$ de solución de veneno a cada ratón. Se registró la cantidad de ratones vivos/muertos (V/M) de cada grupo a las 24 y 48 horas. Se tuvo en cuenta la cantidad de ratones muertos de cada caja a las 48 horas para el análisis probit.

\section{Inmunización de Lama glama con veneno de Bothrops atrox} Las inmunizaciones se realizaron en un cepo o manga de inoculación para animales mayores. Se rasuró la lana de la zona de inoculación en el dorso de la llama y se inoculó el veneno, una mezcla de relación 1:1 entre el veneno y el adyuvante GERBU ${ }^{(9,10)}$, su volumen total fue de $4 \mathrm{~mL}$ ( $2 \mathrm{~mL}$ de veneno y $2 \mathrm{~mL}$ del adyuvante GERBU). Se inoculó el veneno por vía subcutánea (distribuido proporcionalmente en cuatro lugares del dorso y alternando entre ambas partes laterales del lomo entre cada inoculación).

\section{Esquema de inmunización de llama con veneno de Bothrops atrox} El esquema primario de inmunización comprendió 8 inmunizaciones con veneno total de Bothrops atrox más el adyuvante GERBU en la proporción 1:1 (V/V). Las cantidades de veneno inoculadas en cada dosis de inmunización, así como los intervalos de tiempo entre las dosis, se indican en el material suplementario. Luego del esquema primario se aplicaron 7 dosis de refuerzo, según se indica en la Tabla 1.

\section{Obtención de suero de Lama glama}

Se tomó una muestra de sangre (20 mL aprox.) de la vena yugular derecha con una jeringa de $20 \mathrm{~mL}$ utilizando una aguja n. ${ }^{\circ} 18$. La sangre fue colectada en tubos vacutainer que contienen un gel separador para colección de suero y se procedió a centrifugar a $3000 \mathrm{rpm}$ por 5 minutos. El suero se colectó en tubos de microcentrifuga de $1,5 \mathrm{ml}$ que se guardaron a $-80^{\circ} \mathrm{C}$. El suero preinmune se obtuvo antes de la primera inmunización y los sueros posinmunización fueron colectados el mismo día antes de cada inmunización (Tabla 1).

ELISA para la medición de anticuerpos de Lama glama contra el veneno de Bothrops atrox

Se diluyó el veneno en buffer carbonato $\left(\mathrm{Na}_{2} \mathrm{CO}_{3} 0,015 \mathrm{M}\right.$, $\mathrm{NaHCO}_{3} 0,035 \mathrm{M}$ ) a una concentración final de $0,5 \mu \mathrm{g} / \mathrm{mL}$. Se aplicaron $100 \mu \mathrm{L} /$ pocillo del veneno diluido, se cubrió la placa y se incubó toda la noche a $4^{\circ} \mathrm{C}$. Se removió la solución de veneno por inversión. Se agregaron $250 \mu \mathrm{L}$ del buffer de bloqueo (BSA o leche descremada) en cada pocillo y se incubaron por 1 hora a temperatura ambiente. Los sueros a titular se diluyeron desde 1/200 hasta 1/800 en buffer carbonato; así como el control negativo (suero preinmune) y el blanco (buffer carbonato sin antígeno). Se removió el buffer de bloqueo y se lavó 5 veces, luego se añadió a cada pocillo $100 \mu \mathrm{L}$ del suero a titular y se incubó durante 1 hora a temperatura ambiente, realizándolo por duplicado. Se removió el suero y se lavó 5 veces para luego agregar a cada pocillo $100 \mu \mathrm{L}$ de conjugado (anti-Llama IgG $(\mathrm{H}+\mathrm{L})$-Peroxidasa) diluido 1:10 000 en buffer de dilución de conjugado; se incubó durante 1 hora a temperatura ambiente, se removió el conjugado y se lavó 5 veces; a cada pocillo se añadió $100 \mu \mathrm{L}$ del sustrato TMB (tetrametil-benzidina) y se incubó de 5 a 15 minutos a temperatura ambiente y en oscuridad. A cada pocillo se añadió $50 \mu \mathrm{L}$ de solución de parada $\left(\mathrm{H}_{2} \mathrm{SO}_{4}\right)$ 0,5 M. Se leyó la placa a una longitud de onda de $450 \mathrm{~nm}$.

\section{Determinación de la neutralización del efecto letal}

Se siguieron las recomendaciones del manual de procedimientos del Instituto Clodomiro Picado para determinar las actividades tóxicas de venenos y su neutralización ${ }^{(11)}$. Se utilizaron ratones macho de $17 \mathrm{~g}$ a $18 \mathrm{~g}$, se consideraron 5 grupos de 6 ratones por cada caja y una caja adicional para los controles.

Se determinó la dosis de veneno tomando en cuenta 4 veces el valor de la DL5o por cada gramo de ratón a inocular ( $\mu$ g veneno/g ratón). Se utilizó el método de preincubación de veneno con antiveneno (suero de llama) a $37^{\circ} \mathrm{C}$ por 30 minutos, con dosis fijas de veneno $\left(4 \mathrm{DL}_{50}\right)$ y 5 diluciones de veneno. Se determinó el volumen de suero de cada inóculo, partiendo de que $1 \mathrm{~mL}$ de suero debe neutralizar al menos 2,5 mg de veneno (suero antibotrópico-INS). Se preparó la solución de veneno (sin suero) para los ratones control, la cual contiene $4 \mathrm{DL}_{50}$. Se inoculó por vía intraperitoneal un volumen de $0,5 \mathrm{~mL}$ de las soluciones preparadas a cada ratón. Se observó a los ratones en las siguientes horas. Se registró la cantidad de animales V/M de cada grupo a las 24 y 48 
Tabla 1. Esquema de inmunización primaria y refuerzo de Lama glama con veneno de Bothrops atrox

\begin{tabular}{|c|c|c|c|c|}
\hline Día & Veneno de Bothrops atrox & $\begin{array}{c}\text { Volumen de } \\
\text { inoculación }(\mathrm{mL})\end{array}$ & Adyuvante & Procedimiento $^{a}$ \\
\hline 0 & - & - & - & Obtención de suero preinmune \\
\hline \multicolumn{5}{|c|}{ Esquema primario de inmunización } \\
\hline 7 & $0,5 \mathrm{mg}$ & 4 & GERBU & Obtención de suero / inmunización \\
\hline 14 & $1 \mathrm{mg}$ & 4 & GERBU & Obtención de suero / inmunización \\
\hline 21 & $2 \mathrm{mg}$ & 4 & GERBU & Obtención de suero / inmunización \\
\hline 28 & $3 \mathrm{mg}$ & 4 & GERBU & Obtención de suero / inmunización \\
\hline 35 & $4 \mathrm{mg}$ & 4 & GERBU & Obtención de suero / inmunización \\
\hline 42 & $4 \mathrm{mg}$ & 4 & GERBU & Obtención de suero / inmunización \\
\hline 51 & $4 \mathrm{mg}$ & 4 & GERBU & Obtención de suero / inmunización \\
\hline 65 & $4 \mathrm{mg}$ & 4 & GERBU & Obtención de suero / inmunización \\
\hline \multicolumn{5}{|c|}{ Esquema de refuerzo de inmunización } \\
\hline 126 & $4 \mathrm{mg}$ & 4 & GERBU & Obtención de suero / inmunización \\
\hline 201 & $4 \mathrm{mg}$ & 4 & GERBU & Obtención de suero / inmunización \\
\hline 229 & $4 \mathrm{mg}$ & 4 & GERBU & Obtención de suero / inmunización \\
\hline 236 & $4 \mathrm{mg}$ & 4 & GERBU & Obtención de suero / inmunización \\
\hline 245 & $4 \mathrm{mg}$ & 4 & GERBU & Obtención de suero / inmunización \\
\hline 253 & $4 \mathrm{mg}$ & 4 & GERBU & Obtención de suero / inmunización \\
\hline 268 & $4 \mathrm{mg}$ & 4 & GERBU & Obtención de suero / inmunización \\
\hline
\end{tabular}

a Excepto el día 0, se realizó la obtención de suero el mismo día antes de cada inmunización

horas, se tuvo en cuenta la cantidad de ratones muertos de cada caja a las 48 horas para el cálculo estadístico.

\section{Análisis estadísticos}

El análisis estadístico se realizó con el programa Stata versión 11 y la función probit para determinar $\mathrm{la}_{50}$; también se analizaron los datos de neutralización de letalidad para calcular la $\mathrm{DE}_{50}$ del suero. Las diferencias entre los grupos se determinaron con la prueba de Chi cuadrado, considerando estadísticamente significativos los valores de p menores a 0,05.

\section{Aspectos éticos}

El estudio del cual forma parte este artículo fue aprobado por el Comité de Ética Institucional en Seres Humanos y por el Comité de Ética para el Uso de Animales de Experimentación del INS.

\section{RESULTADOS}

$\mathrm{La} \mathrm{DL}_{50}$ del pool de venenos de serpientes peruanas Bothrops atrox fue de 3,96 $\mu \mathrm{g}$ de veneno/g de ratón a las 48 horas, con un límite inferior de $3,57 \mu \mathrm{g} / \mathrm{g}$ y un límite superior de $4,38 \mu \mathrm{g} / \mathrm{g}$, según su intervalo de confianza al 95\%. Además, se encuentra un valor de $\mathrm{R}^{2}$ de 0,99 lo cual indica una alta correlación entre la dosis aplicada y el efecto letal del veneno (Figura 1).
El análisis del veneno de Bothrops atrox por electroforesis por SDS-PAGE muestra un perfil característico de proteínas que concuerda con el perfil de proteínas reportado para esta especie ${ }^{(6)}$. Se observaron cuatro bandas fuertes (proteínas más abundantes) y al menos 6 bandas tenues; entre las proteínas más abundantes, dos bandas de alto peso molecular (45$60 \mathrm{kDa})$ y dos bandas de menor peso molecular (10-20 kDa) (Figura 2A). En el análisis de electroforesis del suero se observó el perfil de proteínas de bandas correspondientes a las cadenas pesadas y ligeras de los anticuerpos IgG (Figura 2B).

La estandarización del ensayo de ELISA para detectar anticuerpos contra el veneno de Bothrops atrox en el suero de llama demostró que la cantidad óptima de antígeno a utilizar es de $50 \mathrm{ng}$, la dilución óptima del suero es de 1:800 y la dilución ideal del anticuerpo conjugado con peroxidasa es de 1:10 000 . La albúmina sérica bovina (BSA) resultó ser un mejor agente bloqueante que la leche descremada para el ELISA. Para elegir los parámetros óptimos del ensayo se consideró la diferencia de absorbancia entre el suero control preinmune y el suero inmune. El título de anticuerpos específicos para el veneno de Bothrops atrox se incrementó rápidamente en el suero a partir de la segunda semana después del inicio de las inmunizaciones alcanzando el máximo en la cuarta semana y luego manteniéndose constante.

Al término de la inmunización primaria no se logró la potencia esperada, similar a la del suero de referencia (suero equino) $(2,5 \mathrm{mg} / \mathrm{mL})$; por lo tanto, luego de este primer 


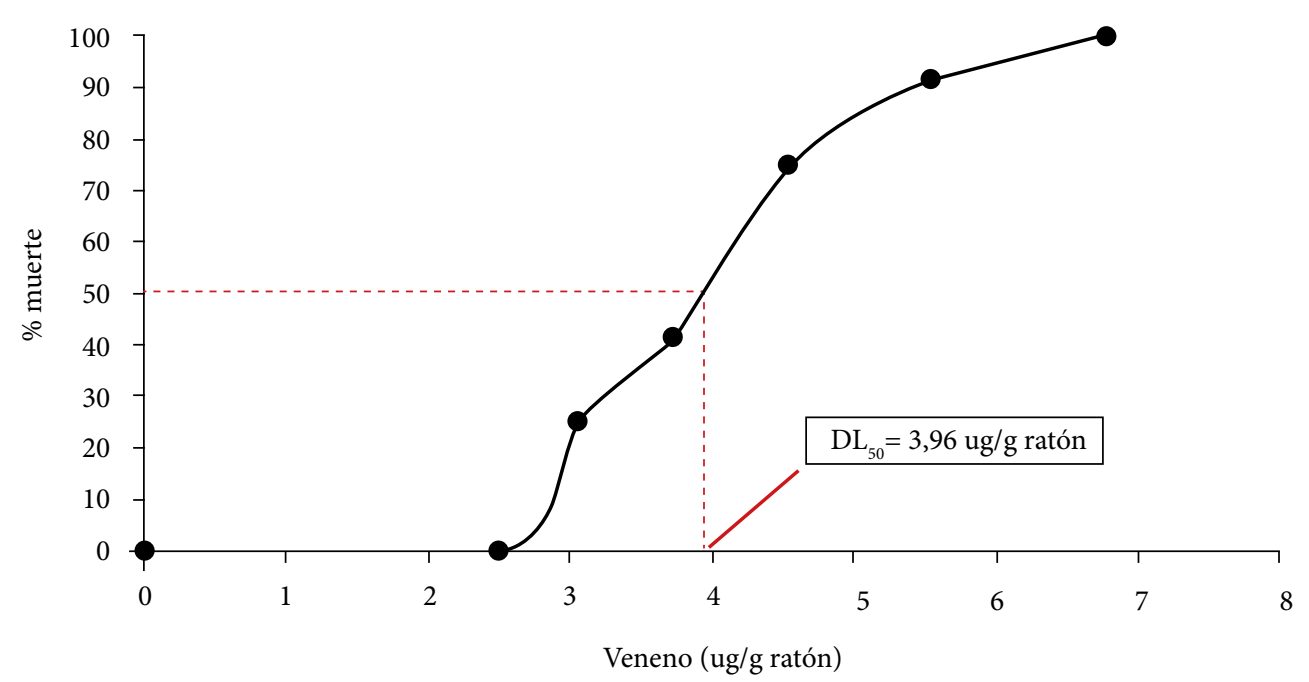

Figura 1. Determinación de dosis letal media $\left(\mathrm{DL}_{50}\right)$ del veneno de serpiente Bothrops atrox. Se evaluaron diferentes cantidades de veneno, desde 2,5 hasta 6,75 ug de veneno por gramo de ratón en grupos de 12 ratones. Se inocularon las soluciones de veneno por vía intraperitoneal y se contaron los ratones vivos y muertos a las 48 horas

esquema se procedió a realizar siete refuerzos de inmunización de $4 \mathrm{mg}$ de veneno en volumen de $2 \mathrm{~mL}$, hasta lograr que la potencia neutralizante fuese igual o mayor a $2,5 \mathrm{mg} / \mathrm{mL}$. Luego de los refuerzos la $\mathrm{DE}_{50}$ fue $3,30 \mu \mathrm{L} / \mathrm{g}$ ratón y los limites superior e inferior fueron $3,86 \mu \mathrm{L} / \mathrm{g}$ ratón y $2,90 \mu \mathrm{L} / \mathrm{g}$ ratón, respectivamente. Esta $\mathrm{DE}_{50}$ equivale a una potencia de neutralización del veneno de $3,6 \mathrm{mg} / \mathrm{mL} ; 1 \mathrm{~mL}$ de suero de llama es capaz de neutralizar 3,6 mg de veneno de Bothrops atrox. Se realizó una comparación entre los títulos de anticuerpos y las potencias para estas fechas (Figura 3).

A

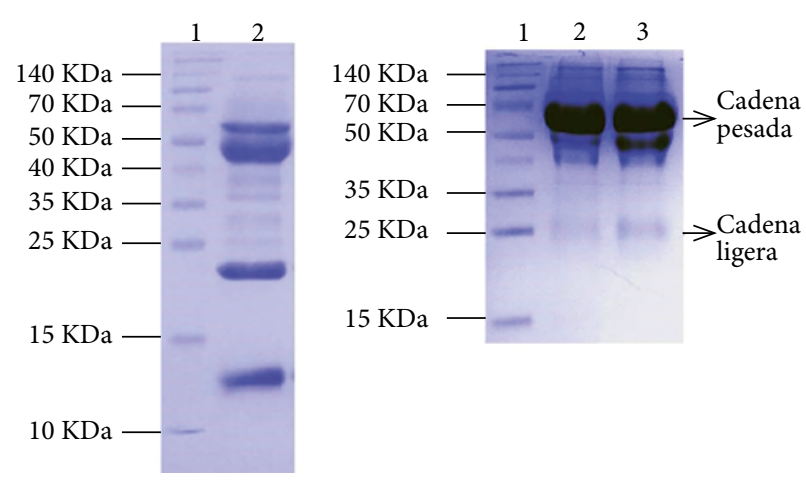

Figura 2. Electroforesis SDS-PAGE del veneno de Bothrops atrox y suero de llama. A) Perfil de proteínas del veneno de serpiente Bothrops atrox. Carril 1: marcador de peso molecular de proteínas (Termo Scientific \#26623). Carril 2: veneno total de Bothrops atrox. B) Electroforesis del suero de llama (Lama glama). Carril 1: marcador de peso molecular de proteínas (Thermo Scientific \#26623). Carril 2: suero preinmune de llama. Carril 3: suero inmune de llama

\section{DISCUSIÓN}

Si bien los antivenenos producidos en equinos son el principal tratamiento utilizado en los casos de ofidismo, aún existen algunos problemas asociados al uso de los antivenenos, como la aparición de reacciones adversas en los pacientes ${ }^{(3)}$. El presente estudio analiza la respuesta inmune de la llama al veneno de la serpiente Bothrops atrox y la capacidad de este suero hiperinmune para neutralizar la letalidad del veneno, como una aproximación para evaluar otras especies seroproductoras.

Ruiz et al. ${ }^{(12)}$ determinaron una $\mathrm{DL}_{50}$ de Bothrops atrox intraperitoneal a las 48 horas de $2,3 \mathrm{mg} / \mathrm{kg}$. Por otro lado, Ohsaka ${ }^{(13)}$ determinó una $\mathrm{DL}_{50}$ de $3,8 \mu \mathrm{g} / \mathrm{g}$ a las 48 horas $\mathrm{y}$ por vía intraperitoneal. Barros et al. ${ }^{(14)}$ determinaron una $\mathrm{DL}_{50}$ de $6,85 \mu \mathrm{g} / \mathrm{g}$, y Meier y Theakston ${ }^{(15)}$ determinaron un $\mathrm{DL}_{50}$ de 3,95 $\mu \mathrm{g} / \mathrm{g}$ en las mismas condiciones. Comparados con nuestros resultados de $3,96 \mu \mathrm{g} / \mathrm{g}$ estos valores son similares, debido a que el ensayo es el mismo y las muestras biológicas son de la misma especie. Las diferencias podrían deberse a variaciones entre las poblaciones de serpientes estudiadas, ya que las características de los venenos de una misma especie de serpiente pueden variar en función de la edad de los especímenes, su origen o si se encuentran en estado silvestre o en cautiverio ${ }^{(4,16)}$.

Estudios previos ${ }^{(17)}$ muestran que los venenos botrópicos son entre 1,2 y 3,6 veces más tóxicos cuando se inoculan por la vía endovenosa que por la vía intraperitoneal. También los datos previos sugieren que la vía subcutánea no es recomendable para la evaluación de la potencia tóxica ${ }^{(17)}$. 


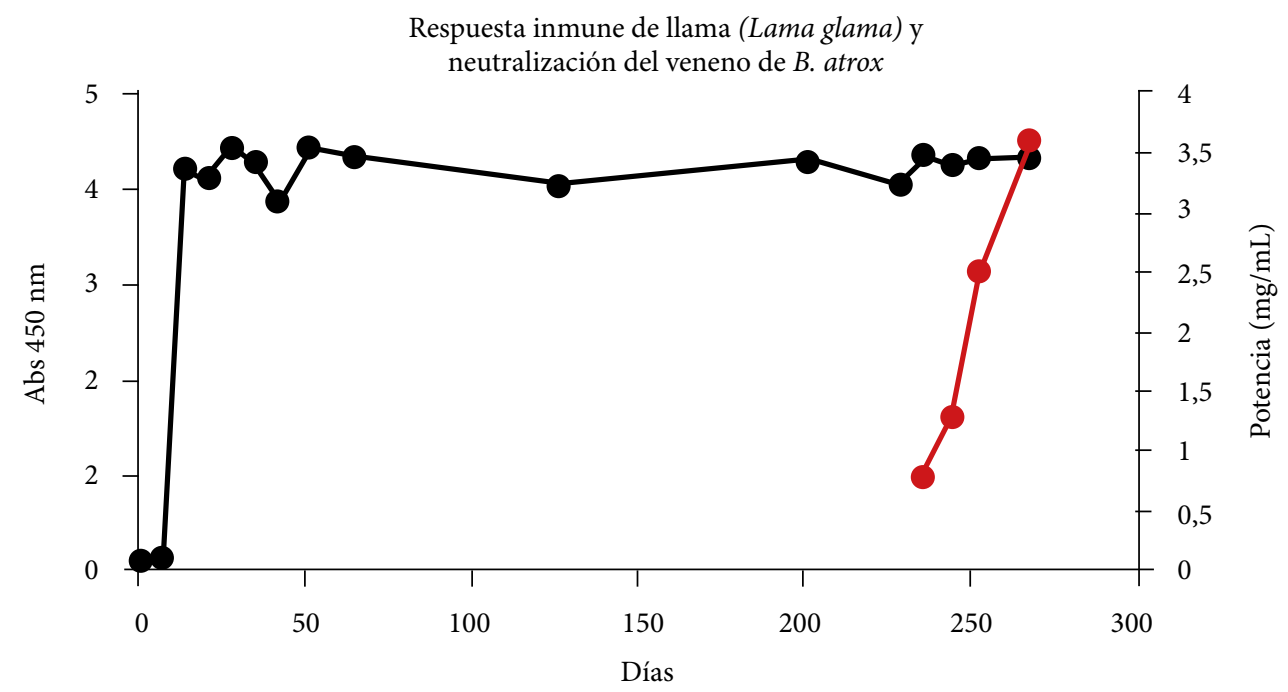

Figura 3. Medición de anticuerpos contra veneno de Bothrops atrox por ELISA y neutralización del efecto letal en ratones. Se midieron los anticuerpos en el suero de llama luego de las inmunizaciones por el ensayo de ELISA (valores en eje Y izquierda, línea de color negro), y se analizó la potencia de neutralización de letalidad en ratones del suero hiperinmune de llama, en ratones de laboratorio (valores en eje Y derecho, línea de color rojo)

Por estas razones, en este estudio se utilizó la inoculación por vía intraperitoneal, mostrando buenos resultados en el ensayo de neutralización de letalidad.

Los antivenenos producidos en caballos son evaluados por las mismas instituciones que las fabrican, en nuestro caso el INS, pero además se realizan estudios para verificar la efectividad que tienen y corroborar cuál es su rango de acción en cuanto a especies de serpientes y verificar su poder de neutralización ${ }^{(18)}$; en nuestro estudio, el suero hiperinmune de llama presentó una potencia de neutralización de $3,6 \mathrm{mg} / \mathrm{mL}$; que significa que $1 \mathrm{~mL}$ del suero hiperinmune de llama es capaz de neutralizar 3,6 mg de veneno de Bothrops atrox.

En este trabajo se analizaron los datos dosis-respuesta con el estadístico probit, aunque se encontró en referencias otros tipos más de análisis posibles, se optó por el probit por ser el más adecuado para el ensayo. Debido a la necesidad de obtener datos objetivos, la estadística se ha usado desde hace décadas y conforme ha ido avanzando se han ideado algunas formas de calcular el $\mathrm{DL}_{50}$. Por ejemplo, en 1985 Meier y Theaicston ${ }^{(15)}$ propusieron un método de análisis estadístico para reducir la cantidad de ratones de experimentación de 30 a 10 que no diferían significativamente en sus resultados siendo más deseable por motivos económicos y éticos. Pero esto ha sido superado posteriormente por el estadístico probit, que es muy útil frente a datos dosis-respuesta de este tipo.

Ya en trabajos anteriores se demostró el gran valor del uso de la técnica ELISA en ensayos in vitro para el análisis de anticuerpos generados en respuesta a la inmunización con venenos, en comparación con otros métodos usados anteriormente como inmunodifusión o hemaglutinación ${ }^{(19)}$.
No se observó una concordancia simultánea entre el título de anticuerpos y la capacidad de neutralización durante el proceso de inmunización, ya que los anticuerpos contra el veneno de Bothrops atrox se incrementan rápidamente, pero la potencia de neutralización se incrementa más lentamente y requiere más tiempo y la administración de dosis de refuerzo de inmunización.

Otros estudios con suero de llama tampoco encontró una correlación entre el título y la efectividad de neutralización de venenos en ensayos preclínicos ${ }^{(20)}$. Esta observación se debe probablemente a que el ensayo de ELISA detecta tempranamente todos los anticuerpos producidos contra todos los antígenos del veneno; mientras que el efecto de neutralización solo depende de un grupo pequeño de anticuerpos específicos que neutralizan o bloquean la toxicidad producida por las toxinas o proteínas del veneno.

El desarrollo lento de la potencia de neutralización en llama es comprensible, considerando que en caballos también se requieren en total de 12 dosis o más de inmunización, para alcanzar los valores esperados de potencia de neutralización del veneno ${ }^{(21)}$.

Harrison et al. ${ }^{(22)}$ midieron la capacidad neutralizante del suero hiperinmune de Lama glama contra el veneno de Echis ocellatus, y encontraron que se produce un título elevado de anticuerpo de llama a las dos semanas, similar a nuestros resultados, ambos trabajos indican que es factible preparar antisuero botrópico a partir del suero de llama. Además, encontraron un componente aún no determinado dentro del suero de llama que no es un IgG y que presenta actividad antihemorrágica. Fernandez et al. ${ }^{(23)}$ encontraron que el suero de llama es efectivo contra el veneno de la 
serpiente Bothrops mattogrossensis que también representa una alternativa valiosa para la fabricación de antídotos en Sudamérica.

Entre las limitaciones del estudio se debe considerar que solo se ha evaluado la respuesta inmune al veneno de serpiente Bothrops atrox en una sola llama y es recomendable hacer el análisis en más de un animal; tampoco se ha comparado la capacidad neutralizante del suero de llama contra el suero antibotrópico producido en equino, debido a que este último es un suero polivalente y el suero de llama es solo contra el veneno de la serpiente Bothrops atrox. Se debe resaltar que este es uno de los pocos estudios que evalúan la capacidad neutralizante del suero de llama contra el veneno de serpientes, $y$, aunque existen otros trabajos similares con el veneno de serpientes del género Bothrops, como Bothrops matogrosensis, este el único estudio conocido con la especie Bothrops atrox.

En conclusión, los resultados muestran que el suero hiperinmune de llama tiene actividad neutralizante para el veneno de Bothrops atrox de Perú, con una $\mathrm{DE}_{50}$ de $3,30 \mu \mathrm{L}$ de suero/g ratón y una potencia de neutralización del veneno de $3,6 \mathrm{mg} / \mathrm{mL}$, lo cual significa que $1 \mathrm{~mL}$ de suero hiperinmune es capaz de neutralizar 3,6 mg de veneno. $\mathrm{La} \mathrm{DL}_{50}$ del veneno de Bothrops atrox de Perú fue de 3,96 $\mu$ g veneno/g ratón y se utilizó cuatro veces esta cantidad como dosis de desafío para

\section{REFERENCIAS BIBLIOGRÁFICAS}

1. Loja OD, Aviles GR, Necochea VY, Vilca VM, Castro TJ. Ofidismo por Bothrops atrox: estudio clínico-epidemiológico. Diagnóstico. 2000;39(5):261-5.

2. Poggi D. Veneno de serpiente en la industria e investigación farmacológica-Plan estratégico de desarrollo de la bioindustria en el eje Amazonas-Marañón [Internet]. 2002. Disponible en: http://www.iiap.org.pe/ upload/publicacion/CD_PEBIAM/documentos/BIO\%203/BIO3-A.pdf.

3. Ministerio de Salud. Norma Técnica N ${ }^{\circ}$ 007-MINSA-DGSP. MINSA 2004 Sobre Prevención y Tratamiento De Accidentes Por Animales Ponzoñosos [Internet]. Lima: MINSA; 2004. Disponible en: http://bvs.minsa.gob.pe/ local/dgsp/123_NTPONZONOSOS.pdf.

4. Zelanis A, Tashima AK. Unraveling snake venom complexity with 'omics' approaches: challenges and perspectives. Toxicon. 2014;87:131-4. doi 10.1016/j.toxicon.2014.05.011.

5. Mora D. Productividad Antiofídica De Equinos Destinados a la Industria Inmunobiológica en Costa Rica. Nutrición Animal Tropical. 2014;8(1):44-54.

6. Segura A, Castillo MC, Núñez V, Yarlequé A, Gonçalves LR, Villalta M, et al. Preclinical assessment of the neutralizing capacity of antivenoms produced in six Latin American countries against medically-relevant Bothrops snake venoms. Toxicon. 2010;56(6):980-9. doi: 10.1016/j. toxicon.2010.07.001.

7. Rodríguez S. Negrin A, Burger M. Efecto adverso por suero antibothrópico. Rev Med Uruguay. 2004; 20:228-32.

8. Instituto Nacional de Salud. Guía de Manejo y Cuidado de Animales de Laboratorio: ratón [Internet]. Lima: MINSA, INS; 2008. Disponible en: https://www.ins.gob.pe/insvirtual/images/otrpubs/pdf/GUIA_ANIMALES_RATON.pdf.

9. Grubhofer NA. Vaccine Adjuvants Revisited. TOVSJ. 2008;2:63-67.

10. Pardon E. A general protocol for the generation of Nanobodies for structural biology. Nat Protoc. 2014;9(3):674-93. doi: 10.1038/nprot.2014.039. analizar la neutralización del veneno. La respuesta inmune de la llama al veneno es rápida, con altos títulos de anticuerpos desde la segunda semana de inmunización, pero se requieren varias semanas más y dosis adicionales de refuerzo para alcanzar la potencia esperada de neutralización del veneno por este suero hiperinmune. La prueba ELISA es un buen método in vitro de análisis de anticuerpos generados ante la inmunización con veneno de Bothrops atrox y permite monitorear la respuesta inmune durante la inmunización.

Contribuciones de los autores: HBC, EGC, VOYC, CPR, OCR, $\mathrm{CBF}, \mathrm{BTF}$ han participado en el diseño del artículo, recolección de resultados, análisis de datos, redacción del artículo, revisión del artículo, aprobación de la versión final. MGP, DGN, RIA, SSO, HMA han participado en la recolección de resultados, análisis de datos, revisión del artículo y aprobación de la versión final.

Fuentes de financiamiento: El presente artículo deriva de un estudio más amplio financiado por el Fondo Nacional de Desarrollo Científico, Tecnológico y de Innovación Tecnológica (FONDECYT, Perú) Convenio N.o 188-2015-FONDECYT, además del financiamiento no monetario del INS.

Conflicto de interés: Los autores declaran no tener ningún conflicto de interés.

Material suplementario: Disponible en la versión electrónica de la RPMESP.

11. Instituto Clodomiro Picado. Determinación de actividades Tóxicas de venenos de serpientes y su neutralización por antivenenos. Manual de métodos de laboratorio [Internet]. Costa Rica: Universidad de Costa Rica, Facultad de Microbiología; 2007. Disponible en: http:// www.icp.ucr.ac.cr/sites/default/files/content/Manual\%20de $\% 20$ procedimientos $\% 20$ determinacion $\% 20$ actividades $\% 20$ toxicas $\% 20$ de\%20venenos\%20de\%20serpientes\%20y\%20su\%20neutralizaci\%C3\%B3n.pdf.

12. Ruiz RI, Ruiz LI, Martínez-Vargas AZ, Arruz MS, Gutiérrez JM. Toxicidad y neutralización de venenos ofídicos peruanos de los géneros Bothrops y Lachesis (Serpentes: Viperidae). Rev Biol Trop.1993;41(3A): 351-7.

13. Ohsaka A. Hemorrhagic, necrotizing and edema-forming effects of snake venoms. In: Handbook of Experimental Pharmacology. Volume 52. Berlin: Springer-Verlag;1979.

14. Barros SF, Friedlanskaia I, Petricevich VL, Kipnis TL. Local inflammation, lethality and cytokine release in mice injected with Bothrops atrox venom. Mediators Inflamm. 1998;7(5):339-46. doi: 10.1080/09629359890866.

15. Meier J, Theakston RD. Approximate LD50 determinations of snake venoms using eight to ten experimental animals. Toxicon. 1986;24(4):395-401. doi: 10.1016/0041-0101(86)90199-6.

16. Sousa LF, Portes-Junior JA, Nicolau CA, Bernardoni JL, Nishiyama-Jr MY, Amazonas DR, et al. Functional proteomic analyses of Bothrops atrox venom reveals phenotypes associated with habitat variation in the Amazon. J Proteomics. 2017;159:32-46. doi: 10.1016/j. jprot.2017.03.003.

17. Olascoaga ME. Estudio del veneno de Bothropspictus: bioquímica, toxicidad, neutralización y efectos biológicos [Tesis doctoral]. Lima: Universidad Nacional Agraria La Molina; 1987.

18. Otero R, Núñez V, Barona J, Díaz A, Saldarriaga M. Características bioquímicas y capacidad neutralizante de cuatro antivenenos polivalentes frente a los efectos farmacológicos y enzimáticos del veneno de Bothrops asper 
y Porthidium nasutum de Antioquia y Chocó. Latreia; 2002,15(1):5-15.

19. Sandoval G, Mendoza J, Roldán W, EspinozaY, Solis, H, Yarlequé A. Inmunogenicidad del veneno de Bothrops atrox (Ophidia: Viperidae) y su evaluación por métodos inmunoenzimáticos. Rev Peru Biol; 2011;18(3):335-42.

20. Cook D, Owen T. Analysis of camelid antibodies for antivenom development: Neutralisation of venom-induced pathology. Toxicon. 2010;1;56(3):373-80. doi: 10.1016/j.toxicon.2010.04.005.

21. Espino-Solis G. Los caballos y la producción de antivenenos. [Internet]. Hypatia. 2010; 36(4). Disponible en: https://revistahypatia. org/216.
22. Harrison RA, Hasson SS, Harmsen M, Laing GD, Conrath K, Theakston RD. Neutralisation of venom-induced haemorrhage by IgG from camels and llamas inmunised with viper venom and also by endogenous, non-IgG components in camelid sera. Toxicon. 2006;47(3):3648. doi: 10.1016/j.toxicon.2005.10.017.

23. Fernández GP, Segura A, Herrera M, Velasco W, Solano G, Gutiérrez $\mathrm{JM}$, et al. Neutralization of Bothrops mattogrossensis snake venom from Bolivia: experimental evaluation of llama and donkey antivenoms produced by caprylic acid precipitation. Toxicon. 2010; 55(2-3):642-5. doi: 10.1016/j.toxicon.2009.07.031. 